\title{
Aggregation and Applied Trade Theory
}

\author{
Henry Thompson \\ Auburn University
}

\begin{abstract}
The influence of data aggregation on applied trade theory may not be generally appreciated. Aggregation can have a direct impact on the direction of trade, factor intensity, factor abundance, factor substitution, product differentiation, and intraindustry trade. This paper develops some propositions for applied trade theorists on the effects of aggregation.
\end{abstract}

- JEL Classifications: F10, F11, F12

- Key words: Aggregation, Applied trade theory, Homogeneous, Heterogeneous, Intra-industry trade

\section{Introduction}

Explaining the observed trade patterns with only homogenous products requires too much fine tuning of technology to be convincing. The broad structure of world trade is more naturally explained with the aid of product differentiation than without it. (Elhanan Helpman, 1999)

A preliminary issue for applied trade theorists is the choice between models with homogeneous and heterogeneous products. The level of data aggregation would ideally describe the issue at hand with minimal theoretical structure. Aggregation leads to simpler models and data sets but creates distortions by including increasingly dissimilar products in the same categories.

In the applied trade literature, the observation of intra-industry has been used to motivate the theory of product differentiation. Intra-industry trade, however, occurs for the simple reason that even the finest categories in standard industrial

\footnotetext{
*Corresponding address: Henry Thompson, Economics, Auburn University, Auburn, AL 36849, USA, Tel: +1-334-844-2910, Fax +1-334-844-5639, E-mail: thomph1@auburn.edu (C2005-Center for International Economics, Sejong Institution, All Rights Reserved.
} 
classifications contain different products. There are other distortions due to aggregation. Data on factors of production is highly aggregated, and regional aggregation can disguise underlying patterns of production and trade.

Various issues that arise in applications are clarified by focusing on the effects of aggregation. Examples in the present paper develop a series of working propositions on aggregation and applied trade theory.

\section{Aggregation and Product Differentiation}

Suppose we start with the unrealistic assumption that products are separated at the ideal level with the product vector $P_{n}=\left\{g_{i}\right\}, i=1, \ldots, n$. A red 2002 Ford F150 pickup truck with a regular cab, 2-wheel drive, 120 inch wheelbase, V6 4.2 liter engine, style side body, manual 5 speed transmission with overdrive, air conditioning, front and rear antilock brakes, and cloth seats would be in a separate category from a blue one. The order $n$ of the product vector $P_{n}$ is large but finite. Assume products are ranked next to their closest substitute in consumption, with beef closer to pork than leather. Each product is a perfect substitute with itself and a closer substitute for products closer to it in $P_{n}$.

Let ${ }^{c} P_{n}$ represent a partition of $P_{n}$ into $c$ categories. A partition is a collection of disjoint subsets. The standard in macroeconomics is ${ }^{1} P_{n}$ or simply $P_{n}$, useless for trade theory because there must be at least two products to trade. For trade theory, ${ }^{2} P_{n}$ might be $\{\{$ exports $\}$, \{imports $\left.\}\right\}$ or $\{$ gooods $\}$, \{services $\}$.

Consider partitions that do not skip products. With two products, there is only one partition. With three products, there are three partitions

$$
\begin{aligned}
& { }^{1} P_{3}=\left\{\mathrm{g}_{1}, \mathrm{~g}_{2}, \mathrm{~g}_{3}\right\}, \\
& \left({ }^{2} P_{3}\right)_{1}=\left\{\left\{g_{1}, g_{2}\right\}, g_{3}\right\} \\
& \left({ }^{2} P_{3}\right)_{2}=\left\{g_{1},\left\{g_{2}, g_{3}\right\}\right\} .
\end{aligned}
$$

Note there is no $\left\{g_{1}, g_{3}\right\}$ aggregate because $g_{2}$ is between them in $P_{3}$. Given a desire to aggregate, $\left({ }^{2} P_{3}\right)_{1}$ would be chosen if $g_{2}$ is a closer substitute for $g_{1}$ than $g_{3}$. Suppose country $l$ exports $g_{1}$ and $g_{2}$ to country 2 in exchange for $g_{3}$. There is only interindustry trade with $\left({ }^{2} P_{3}\right)_{1}$ but there is intra-industry trade with $\left({ }^{2} P_{3}\right)_{2}$ as pictured in Figure 1.

Proposition 1. Intra-industry trade depends directly on aggregation.

With four products, there are six partitions

$$
\begin{aligned}
& { }^{l} P_{4}=\left\{g_{1}, g_{2}, g_{3}, g_{4}\right\} \\
& \left({ }^{3} P_{4}\right)_{1}=\left\{\left\{g_{1}, g_{2}\right\}, g_{3}, g_{4}\right\}
\end{aligned}
$$


Figure 1. Aggregation: Interindustry $\left({ }^{2} P_{3}\right)_{1}$ or Intra-industry $\left({ }^{2} P_{3}\right)_{2}$ Trade

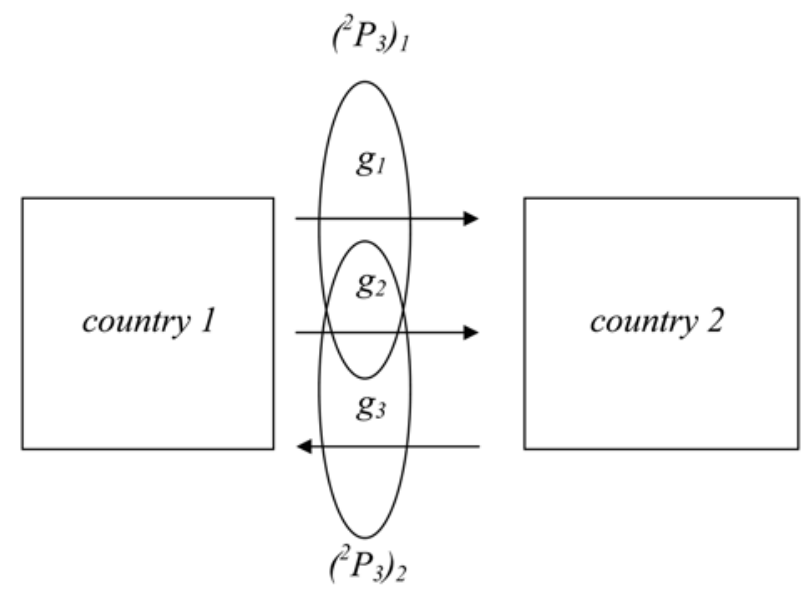

$\left({ }^{3} P_{4}\right)_{2}=\left\{\mathrm{g}_{1},\left\{\mathrm{~g}_{2}, \mathrm{~g}_{3}\right\}, \mathrm{g}_{4}\right\}$

$\left({ }^{3} P_{4}\right)_{3}=\left\{g_{1}, g_{2},\left\{g_{3}, g_{4}\right\}\right\}$

$\left({ }^{2} P_{4}\right)_{1}=\left\{\left\{\mathrm{g}_{1}, \mathrm{~g}_{2}, \mathrm{~g}_{3}\right\}, \mathrm{g}_{4}\right\}$

$\left({ }^{2} P_{4}\right)_{2}=\left\{g_{1},\left\{g_{2}, g_{3}, g_{4}\right\}\right\}$.

If two countries trade the four products in (2), many different patterns of interindustry or intra-industry trade could arise based on the choice of partition or aggregation.

With $n$ products in $P_{n}$ there are $n^{2}-(1+2+\ldots+n)$ possible partitions. The OECD collects SITC (Standard Industrial Trade Classification) data for 68 products, implying 2,278 possible partitions. There is also SIC (Standard Industrial Classification) data available for trade in 1008 products at the 4-digit level, implying 7,158,527 possible partitions. The choice of partition will affect observed intra-industry trade.

A category becomes more "differentiated" when a product is added. For example, if $\left({ }^{3} P_{4}\right)_{1}$ is "aggregated" to $\left({ }^{2} P_{4}\right)_{1}$ in (2) there would be one less product category and a higher "degree" of product differentiation in the category containing $g_{1}$ and $g_{2}$. There has to be more products in at least one group of ${ }^{i} P_{n}$ compared to ${ }^{j} P_{n}$ when $i<j$.

Proposition 2. The "degree" of product differentiation depends on aggregation. A high degree of product heterogeneity remains at the finest level of standard industrial data. One example is SITC Division 65, "textile yarn, fabrics, made-up articles, and related products." In the more finely separated SIC data set, Category 5084 "Industrial machinery and equipment" contains "fans, industrial wholesale" 
and "trucks, industrial wholesale." It should be little surprise that even at the most disaggregated level of data most countries import and exports most categories.

Proposition 3. The finest categories in standard industrial data contain what would have to be called different products.

Chipman (1992) makes the point that intra-industry trade would be eliminated with enough disaggregation. With the perfectly separated products in $P_{n}$, there would be no reason for intra-industry trade apart from relative transport costs. Traders in fact distinguish between different types of even the most basic commodities such as \#2 red wheat or light crude oil.

Proposition 4. With perfectly separated data, there would be virtually no intraindustry trade.

While perfectly homogeneous products may not be observable in practice, homogeneity may be a successful theoretical assumption. The scientific issue is whether the trade theorems based on homogeneous products can be rejected as null hypotheses. Similarly, propositions based on theories of heterogeneous products should be tested as null hypotheses.

\section{Aggregation and the Intra-industry Trade Index}

The level of intra-industry trade in a category of differentiated products can be gauged by an index due to Grubel and Lloyd (1971),

$$
I=(X-M) /(X+M) \text {. }
$$

If $I>0(<0)$ the product is a net export (import). If the product is only exported, $I=1$. If it is only imported $\mathrm{I}=-1$. The highest level of intra-industry trade occurs when $I=0$.

Table 1 presents index $I$ in (3) for SITC Division 7 "machinery and transport equipment" along with its finer Division 78 "road vehicles" for NAFTA, the EU, the US, and the UK. In every instance, aggregation from Division 78 to Division 7 creates more intra-industry trade. This general property of aggregation has been noted in the literature, for instance by Gray (1979), Bergstrand (1983), Greenaway (1983), Tharakan (1984, 1986), and Balassa (1987).

\section{Proposition 5. Aggregation raises the intra-industry trade index.}

An alternative index $I$ ' in Table 1 measures net trade relative to GDP. The EU is a net importer of road vehicles in Division 78 but a net exporter of the aggregate "other machinery and transport equipment" in Division 7. The US and the UK switch rankings of relative intra-industry trade in Division 78. Other possible 
Table 1. Examples of 1996 OECD Intra-industry Trade

\begin{tabular}{c|cccc}
\multicolumn{1}{c}{} & Div 7 & Div78 & Div7 & Div 78 \\
\cline { 2 - 5 } NAFTA & $\mathrm{I}$ & $\mathrm{I}$ & $\mathrm{I}$ ' & I' \\
nyS & .048 & .0053 & .163 & 0049 \\
$E U$ & .097 & .0101 & .461 & .0078 \\
$U K$ & .010 & -.0026 & -.047 & .0018 \\
& 090 & .0075. & .160 & .0150
\end{tabular}

standardizations for a trade index include the trade balance, current account balance, balance of payments, population, and per capita income.

Proposition 6. The choice of standardization can change the direction of trade and relative magnitudes of the intra-industry trade index.

\section{Aggregation and Factor Intensity}

Aggregation of products can alter factor intensity as in the following example from the 1999 US Census of Manufacturing. The products are

$H=$ chemicals

$E=$ electrical machinery

$R=$ rubber $\&$ plastic.

The factors of production are

$C=$ craft workers

$O=$ operators

$T=$ technical workers.

Factor intensity rankings across the three pairs of factors are

$a_{C E} / a_{O E}=0.77>a_{C H} / a_{O H}=0.50>a_{C R} / a_{O R}=0.28$

$a_{T H} / a_{O H}=0.24>a_{T E} / a_{O E}=0.16>a_{T R} / a_{O R}=0.03$

$a_{C R} / a_{T R}=9.33>a_{C E} / a_{T E}=4.81>a_{C H} / a_{T H}=2.08$,

where $a_{i j}$ is the amount of factor $i$ per unit of product $j$. Consider the aggregation of chemicals $H$ and rubber $\&$ plastics $R$ into a product category "chemicals, rubber, plastics" $P$. Continuing with the ranking of factors across products, with two products there is the simplified factor intensity scheme

$$
\begin{aligned}
& a_{C E} / a_{O E}=0.77>a_{C P} / a_{O P}=0.39 \\
& a_{T E} / a_{O E}=0.16>a_{T P} / a_{O P}=0.13 \\
& a_{C E} / a_{T E}=4.81>a_{C P} / a_{T P}=2.89 .
\end{aligned}
$$

There are some intensity relationships hidden by the aggregation from (4) to (5). Consider the relative input of technical workers $T$ and operators $O$ in (4b) and (5b). 
The chemical industry $H$ uses operators the least intensively in (4b) but its aggregate product $P$ uses operators $O$ intensively in (5b). As another example, rubber \& plastic $R$ uses technical workers $T$ the least intensively in (4c) but its aggregate product $P$ uses technical workers $T$ intensively relative to craft workers $C$ in $(5 \mathrm{c})$.

Proposition 7. Aggregation can reverse factor intensity.

\section{Geographical Aggregation}

Geographical aggregation can also introduce distortions. National borders partition the earth's surface, and different partitions would result in different trade patterns. Consider the changing appearance of the "international" trade data due simply to the new national borders of the Soviet Union, Balkans, and the EU.

In Table 1, UK exports of road vehicles would be hidden by its geographical aggregation into the EU. As another example of geographical distortion, Table 2 presents the OECD record of EU trade in meat (SITC 301) in 1996 with the US and NAFTA. The EU has a surplus with the US but deficits with Canada and Mexico. Aggregation to NAFTA would disguise EU imports from Canada and Mexico.

Table 2. EU Trade in Meat with the US and NAFTA, OECD 1999

\begin{tabular}{c|ccc}
\multicolumn{1}{c}{ US } & exports & imports & balance \\
\cline { 2 - 4 } NAFTA & $\$ 270$ & $\$ 251$ & $\$ 19$ \\
& $\$ 291$ & $\$ 336$ & $-\$ 55$
\end{tabular}

Proposition 8. Geographical aggregation can alter the direction of trade.

In a world without national borders, applied trade theorists could search for the geographical aggregation that would optimally explain the pattern of trade. As an example, regional or interstate trade in the US might coincide with particular trade models better than trade between the US and the rest of the world.

\section{Aggregation of Factors}

Data for factors of production are generally scarcer and more aggregated than data for products. There are fewer separate categories, unless factors are considered industry specific. Clark, Hofler, and Thompson (1985) find that the eight categories 
of skilled labor reported by the US Census of Manufacturing cannot be aggregated in any way.

Proposition 9. There are at least as many different categories of skilled manufacturing labor as available in the most detailed US manufacturing data.

There is a vast literature on the difficulty of estimating capital input and separating the influence of technology. Some manufacturing data includes estimates of capital structures and machinery and equipment. Capital input is most often estimated from the residual of value added after other estimated inputs are subtracted.

An unsettling property from applied production theory is that factor aggregation alters the estimates of cross price substitution between factors not involved in the aggregation, and in ways that are impossible to predict. Substitution involving the aggregated factors generally diminishes. Berndt and Christensen (1973) and Diewert (1974) explore the links between aggregation and estimates of factor substitution.

Proposition 10. Aggregation distorts estimates of cross price factor substitution.

Factor aggregation may also reverse factor intensity. Consider the aggregation of clerical $C$ and technical workers $T$ into skilled labor $S$ in (4). With the two remaining factors, there is a single factor intensity ranking across products

$$
a_{S E} / a_{O E}=0.93>a_{S H} / a_{O H}=0.74>a_{S R} / a_{O R}=0.31 \text {. }
$$

Relative to the electric machinery industry $E$, the chemicals industry $H$ uses technical workers $T$ intensively relative to operators in (4a) but uses operators intensively relative to the aggregate skilled labor $S$ in (6).

Proposition 11. Aggregation of factors may reverse factor intensity.

Analogously, aggregation can reverse factor abundance across countries.

Proposition 12. Aggregation of factors may reverse factor abundance.

\section{Conclusion}

Trade theory is based on efficiency gains that occur with specialization. Comparative advantage leads to gains from trade in models with competition, constant returns, and homogeneous products. In models with imperfect competition, increasing returns, or differentiated products, there can be various other sources of gains from trade. Competition and monopoly are industrial organizations that involve interindustry trade in homogeneous products. Monopolistic competition of Chamberlain (1933), Lancaster (1980), and Helpman 
and Krugman (1985) is an industrial organization that involves intra-industry trade in differentiated products. For applied trade theory, the purpose and tastes of the researcher determine the choice of model and industrial structure.

Factor proportions theory and its underlying competitive models have been called failures in the literature based on empirical results from highly aggregated data. The "missing trade" discussed by Trefler (1993) is due in part to missing detail in the data. Davis and Weinstein (1999) uncover missing theoretical assumptions but use highly aggregated data.

More detailed disaggregated studies will ultimately supplement intuition based on highly aggregated data. Whether the broad structure of world trade is more naturally explained with highly disaggregated homogeneous products or with product differentiation remains an open question.

\section{Acknowledgments}

Thanks for suggestions go to Farhad Rassekh, Roy Ruffin, and a referee of this journal.

Received 29 March 2001, Accepted 11 December 2004

\section{References}

Balassa, B. (1987) Intra-industry Specialization: A Cross-Country Analysis, European Economic Review, 30, 27-42.

Bergstrand, J. (1983) Measurement and Determinants of Intra-industry International Trade, in Intra-Industry Trade: Empirical and Methodological Aspects, (Ed.) Tharakan, P.K.M., North Holland, Amsterdam

Berndt, E., Christensen, L. (1973) The Internal Structure of Functional Relationships:

Separability, Substitution, and Aggregation, Review of Economic Studies, 50, 403-10 Chamberlain, E.H. (1933) The Theory of Monopolistic Competition, Harvard University Press, Cambridge

Chipman, J. (1992) Intra-industry Trade, Factor proportions, and Aggregation," in Economic Theory and International Trade: Essays in Momorium of J. Trout Rader, (Eds.) by Wilhelm Neuefeind, W., Riezman, R., Springer-Verlag, New York

Clark, D., Hofler, R., Thompson, H. (1988) Separability of capital and labor in US Manufacturing, Economics Letters, 27, 197-201.

Davis, D. and Weinstein, D. (2001) An Account of Global Factor Trade, American Economic Review, 91, 1423-53. 
Diewert, W.E. (1974) A Note on Aggregation and Elasticities of Substitution, Canadian Journal of Economics, 7, 12-20.

Gray, P. (1979) Intra-industry Trade: The Effects of Different Levels of Data Aggregation, in On the Economics of Intra-industry Trade, (Ed.) Giersch, H., Mohr, Tubingen

Greenaway, D. (1983) Patterns of Intra-industry Trade in the United Kingdom, in IntraIndustry Trade: Empirical and Methodological Aspects, (Ed.) Tharakan, P.K.M., North Holland, Amsterdam

Grubel, H.G., Lloyd, P. (1971) The Empirical Measurement of Intra-industry Trade, Economic Record, 47, 494-517.

Helpman, E. (1999) The Structure of Foreign Trade, Journal of Economic Perspectives, 13, 124-44.

Helpman, E., Krugman, P. (1985) Market Structure and Foreign Trade: Increasing Returns, Imperfect Competition, and the International Economy, The MIT Press, Cambridge

Lancaster, K. (1980) Intra-industry Trade under Perfect Monopolistic Competition, Journal of International Economics, 1, 215-26.

Tharakan, P.K.M. (1984) Intra-industry Trade between the Industrial Countries and the Developing World, European Economic Review, 26, 213-27.

Tharakan, P.K.M. (1986) The Intra-industry Trade of Benelux with the Developing World, Weltwirtschaftliches Archiv, 118, 131-49.

Trefler, D. (1985) The Case of Missing Trade and Other Mysteries, American Economic Review, 85, 1029-46. 